\title{
PRETERM BIRTH AND FETAL GROWTH RESTRICTION ARE PERINATAL RISK FACTORS FOR REDUCED EXERCISE CAPACITY IN HEALTHY YOUNG MEN
}

\author{
J. Svedenkrans, E. Henckel, J. Kowalski, M. Norman, K. Bohlin \\ Karolinska Institutet and University Hospital, Stockholm, Sweden
}

Background: Physical inactivity and unfitness increase the risk for cardiovascular disease and diabetes. The aim of this study was to investigate the impact of perinatal risk factors on exercise capacity in young men.

Methods: A population-based study linking results from exercise test in young men conscripting for military service (1993-2001) to data from the Medical Birth Register and the National Population and Housing Census 1990. Exercise capacity $\left(\mathrm{W}_{\max }=\right.$ maximal load on test bicycle) was analysed in relation to gestational age (GA), birth weight standard deviation score (BWSDS), parental socioeconomic status and education, as well as blood pressure and body mass index (BMI) in conscripting men. Data were analysed using multiple regression.

Results: The cohort included 218,915 healthy young men (median age 18 years) considered for military service. Preterm birth predicted low $\mathrm{W}_{\text {max }}$ irrespective of BWSDS. In addition, in men born at term, low BWSDS also predicted low $\mathrm{W}_{\max }(\mathrm{P}<0.001$ for interaction between GA and BWSDS). Low parental education level, and both low and high BMI at conscript, were also associated with reduced $\mathrm{W}_{\max }$.

Conclusion: Preterm birth and low birth weight at term are perinatal risk factors for reduced exercise capacity in young men. All men were considered healthy and fit for military service, suggesting the effect could not be explained by major impairment in lung function and motor performance. The effect size of being born too early or too small equal exceed that of other known risk factors for unfitness in adults, such as low education and overweight. 